\title{
Service Delivery Location Code
}

National Cancer Institute

\section{Source}

National Cancer Institute. Service Delivery Location Code. NCI Thesaurus. Code C95394.

A coded value specifying the service delivery location. 